\title{
ORIGINAL ARTICLE \\ Engagement in occupational activities and pressure ulcer development in rehabilitated South Indian persons with spinal cord injury
}

\author{
A Mathew, S Samuelkamaleshkumar, S Radhika and A Elango
}

\begin{abstract}
Study design: Cross-sectional survey.
Objective: To compare the relationship between engagement in occupational activities and pressure ulcer (PU) development in persons with spinal cord injury (SCI).

Study setting: Tertiary care university teaching hospital, Tamil Nadu, India.

Method: One hundred and eight persons with $\mathrm{SCl}$ who were previously rehabilitated from our center were included in the study. A questionnaire was developed to collect information about occupational activities and particulars of PU development.

Results: The comparison between work, self-care and leisure with PU development showed no significant correlation. However, completeness of the SCl was found to be associated with PU development. The study also found a relationship between the type of work patients did and the severity of the PU they developed.

Conclusion: This study clearly indicates that poor pressure relief practices lead to PU development in persons with SCI, irrespective of their level of independence, employment status or leisure pursuits thus hampering their functional independence at home, work and in daily activities that subsequently reduces their quality of life.
\end{abstract}

Spinal Cord (2013) 51, 150-155; doi:10.1038/sc.2012.112; published online 13 November 2012

Keywords: pressure ulcers; work; self-care; leisure; relationship; completeness

\section{INTRODUCTION}

Spinal cord injury (SCI) is a debilitating condition that has a broad impact on the medical, social, psychological and economic aspects of those who are directly affected, their caregivers and the community. ${ }^{1}$ In India, $\sim 1.5$ million people live with SCI. Every year, 10000 new cases are added to this group of individuals. ${ }^{2}$ Most of these spinal cord-injured people, in addition to their injury, suffer from secondary complications, especially pressure ulcer (PU) development. Studies show varying rates of PU development. For the purpose of this study, Correa's ${ }^{3}$ definition of PUs was used. PUs are a common complication following SCI. Prevalence of PUs for persons in the chronic SCI stage varies between 15 and $30 \% .{ }^{4}$ About $30-40 \%$ of patients with spinal cord injuries develop PUs during the acute and rehabilitation phases, most frequently over bony prominences, such as the sacrum, tuber ischii, heel, malleolus and trochanter. ${ }^{5}$ It was also reported that $15-26 \%$ of spinal cord-injured individuals would develop PUs post injury. ${ }^{6}$

The development of PUs is associated with certain risk factors. Some of the major risk factors are decreased activity, immobility and low satisfaction with the activities of daily living. ${ }^{3}$ PUs have a significant negative effect on the general health and quality of life of the patients. ${ }^{3}$ The development of a PU affects the health and occupational status of an individual considerably.

Occupational activities are considered to have three different areas namely work, leisure and daily living tasks, which are important domains of occupational therapy. ${ }^{7}$ Occupational therapy has emerged from the belief that engagement in occupation can affect an individual's health. There is also evidence to support the relationship between occupation, health and well-being. ${ }^{7-10}$ Engagement in occupation contributes to health through an individually balanced use of time, a positive focus for one's physical and mental energy, and the provision of a sense of purpose. ${ }^{11}$

But in SCI, occupation, a part of which is to gain employment, is significantly reduced. Unemployment was also found to be associated with reduced functional independence. ${ }^{12}$ Most common reported barriers to employment were problems with transportation, health and physical limitations, lack of work experience, education or training, physical or architectural barriers, discrimination by employers and loss of benefits. ${ }^{13}$ It was also noted that people with SCI spend more time pursuing passive leisure than productive activities like paid work. ${ }^{14}$

This study aims to explore the relationship between PU development and engagement in occupational activities in persons with SCI. It further analyses the correlation between injury characteristics such as level and completeness of injury with PU development.

\section{MATERIALS AND METHODS \\ Participants}

One hundred and eight persons with SCI who were previously rehabilitated from our rehabilitation center were selected for this study. Patients who had lesion at T2 and below were included. Their age was ranging from 16-65. 
Before data collection, each participant was briefed about the importance of the study and written consent was obtained from them.

\section{Research design}

A retrospective cross-sectional survey was used to collect the information on PU development.

\section{Data collection}

A questionnaire was developed based on previous literature to enable data collection. Most of the questions were closed ended. Few of the questions were open ended to allow greater understanding. The questionnaire consisted of the following sections: (i) Demographic characters, including age, sex, educational status, marital status, duration of illness, level and completeness of the injury; (ii) details on employment status, type of work, time spent on work, satisfaction, previous job, reason for discontinuing and income; (iii) description of participation in leisure, type and time spent on leisure activities; (iv) details on independence in self-care and amount of assistance required; and (v) details on PU occurrence, number, severity, hospitalization, location and cause of ulcer.

The final version of the questionnaire was derived after administering it to 10 patients and discussion with a panel of experts in the field of SCI. The questionnaire was administered by experienced occupational therapists. The administration of the questionnaire took around $20 \mathrm{~min}$ for each participant.

\section{Data analysis}

The data analysis was done using SPSS for windows version 12 (SPSS Inc., Chicago, IL, USA). Pearson's correlation test was used to compare demographic characteristics such as participation in work, leisure and self-care with PU development. Statistical significance was considered at 0.05 level. Descriptive statistics using frequency measures was used to find other details like percentage of employed people and percentage of people with ulcers.

We certify that all applicable regulations concerning the ethical use of human volunteers were followed during the course of this research.

\section{RESULTS}

One hundred and eight participants with SCI participated in this study. Of which, $96(89 \%)$ were males, $68(63 \%)$ were between the age of $16-40,73(68 \%)$ had complete lesions and $82(76 \%)$ were working (Table 1).

It was found that a large portion of the study population, 89 (82\%), had developed PUs post injury. The severity of the ulcer was graded as mild by $38(43 \%)$ participants, moderate by $12(13 \%)$ participants and severe by 39 (44\%) participants (Figure 1).

The comparison between work, self-care and leisure with PU development showed no significant correlation. No significant correlation was found between level of injury and PU development. However, there was a significant correlation between the completeness of lesion and PU development. Participants with complete lesions were more prone to develop ulcers (Table 2).

The employment status post injury showed certain variations with regard to the type of work held by the participants. Office workers were more likely to resume their works. There was a significant drop in the number of manual laborers post injury. The number of participants engaging in home-based occupations had increased (Figure 2).

The study identified that only $18(17 \%)$ participants were continuing their old work, while 77 (71\%) participants had to discontinue their previous work. A large part of the participants, 62 $(57 \%)$, reported that it was owing to the physical limitation caused by the injury that they could not go back to the previous work, while only two $(2 \%)$ participants reported difficulty in transportation as a reason. Nine $(8 \%)$ participants had said that both physical limitation and transportation were issues. Four (4\%) participants reported that
Table 1 Demographic characteristics of study participants

\begin{tabular}{|c|c|c|}
\hline Variable & Frequency & Percentage \\
\hline \multicolumn{3}{|l|}{ Gender } \\
\hline Male & 96 & 89 \\
\hline Female & 12 & 11 \\
\hline \multicolumn{3}{|l|}{ Age } \\
\hline $16-40$ & 68 & 63 \\
\hline $41-65$ & 40 & 37 \\
\hline \multicolumn{3}{|l|}{ Education } \\
\hline No education & 10 & 9 \\
\hline Primary education & 33 & 31 \\
\hline Secondary education & 43 & 40 \\
\hline College & 22 & 20 \\
\hline \multicolumn{3}{|l|}{ Duration of injury } \\
\hline Upto 10 years & 59 & 55 \\
\hline 10-20 years & 42 & 39 \\
\hline More than 20 years & 7 & 6 \\
\hline \multicolumn{3}{|l|}{ Level of injury } \\
\hline High thoracic & 23 & 21 \\
\hline Low thoracic & 49 & 45 \\
\hline Lumbar & 34 & 32 \\
\hline Sacrum & 2 & 2 \\
\hline \multicolumn{3}{|l|}{ Completeness of injury } \\
\hline Complete (ASIA—A) & 73 & 68 \\
\hline Incomplete (ASIA—BCD) & 35 & 32 \\
\hline \multicolumn{3}{|l|}{ Employment status } \\
\hline Working & 82 & 76 \\
\hline Not working & 26 & 24 \\
\hline
\end{tabular}

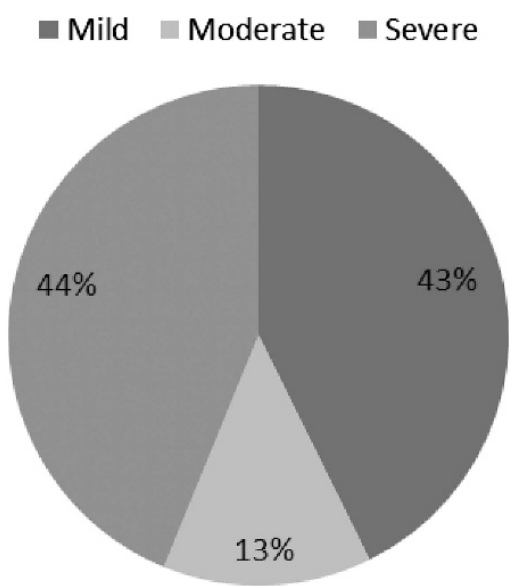

Figure 1 Severity of ulcers among participants.

other reasons like retirement and unavailability of a caregiver were also contributing factors.

The type of work participants engaged in was significantly correlated with the severity of ulcers they developed. Participants who engaged in manual work developed (73\%) less severe ulcers and 
Table 2 Comparison between variables and pressure ulcer development

\begin{tabular}{|c|c|c|c|c|}
\hline Group & $\mathrm{N}$ & $\mathrm{n}$ & $\chi^{2}$-value & P-value \\
\hline \multicolumn{5}{|l|}{ Employment } \\
\hline Working & $82(76 \%)$ & $67(82 \%)$ & 0.548 & 0.892 \\
\hline Not working & $26(23 \%)$ & $22(85 \%)$ & & \\
\hline \multicolumn{5}{|l|}{ Self care } \\
\hline Independent & $33(31 \%)$ & $27(82 \%)$ & 0.011 & 0.915 \\
\hline Dependent & 75 (69\%) & $62(83 \%)$ & & \\
\hline \multicolumn{5}{|l|}{ Leisure } \\
\hline Active & $65(60 \%)$ & $53(82 \%)$ & 2.022 & 0.568 \\
\hline Passive & $41(38 \%)$ & $34(83 \%)$ & & \\
\hline No leisure & $2(2 \%)$ & $2(100 \%)$ & & \\
\hline \multicolumn{5}{|l|}{ Level of injury } \\
\hline High thoracic level & $24(22 \%)$ & $21(88 \%)$ & 2.767 & 0.598 \\
\hline Low thoracic level & $48(45 \%)$ & $39(81 \%)$ & & \\
\hline Lumbar & $34(31 \%)$ & $26(76 \%)$ & & \\
\hline Sacral & $2(2 \%)$ & $2(100 \%)$ & & \\
\hline \multicolumn{5}{|l|}{ Completeness of injury } \\
\hline Complete (ASIA—A) & $73(68 \%)$ & $66(90 \%)$ & 14.678 & 0.001 \\
\hline Incomplete (ASIA-BCD) & $35(32 \%)$ & $21(60 \%)$ & & \\
\hline
\end{tabular}

Abbreviations: $N$, total number of persons; $n$, number of persons with pressure ulcer.

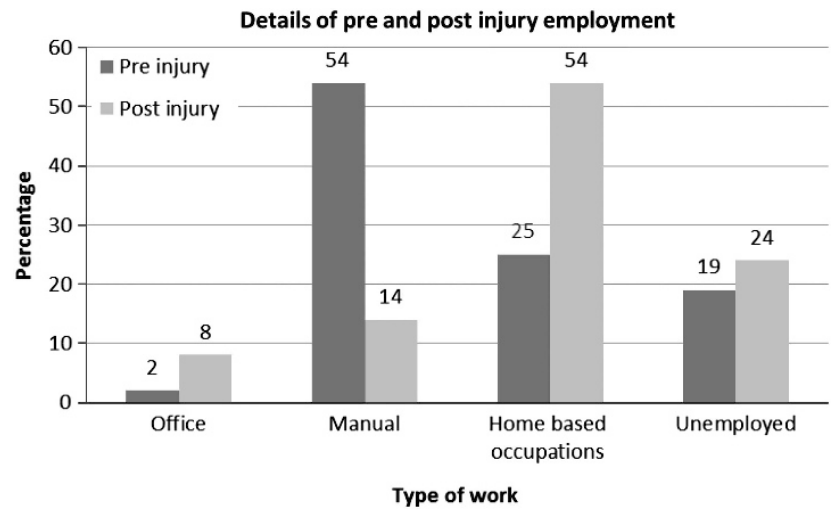

Figure 2 Employment categories before and after the injury.

the participants who engaged in home-based occupations developed (41\%) severe ulcers (Table 3 ).

Poor pressure relief practices is the main cause for development of PUs in majority of our participants (Figure 3).

The highest incidence of pressure ulcers occurred at the sacrum $(72 \%)$, followed by ischium (11\%), heel $(9 \%)$, other areas $(5 \%)$ and the knee (Figure 4).

\section{DISCUSSION}

In this study, $76 \%$ of the participants were employed. The study highlighted that employment rates after SCI was higher than that observed in earlier studies, which states that employment rates after SCI ranged from 13 to $51 \% .{ }^{12}$ A study done in India also found only $41 \%$ employment post injury. ${ }^{2}$
Table 3 Comparison between type of work and severity of pressure ulcers

\begin{tabular}{lrrrrrrr} 
Type of work & $\mathrm{N}$ & $\mathrm{n}(\%)$ & Mild sore & $\begin{array}{c}\text { Moderate } \\
\text { sore }\end{array}$ & $\begin{array}{r}\text { Severe } \\
\text { sore }\end{array}$ & $\begin{array}{c}\chi^{2}- \\
\text { value }\end{array}$ & P-value \\
\hline Office work & 9 & $7(77)$ & $2(22 \%)$ & $3(33 \%)$ & $2(22 \%)$ & & \\
Manual work & 15 & $13(86)$ & $11(73 \%)$ & $0(0 \%)$ & $2(13 \%)$ & 17.597 & 0.040 \\
Home-based & 58 & $47(80)$ & $18(31 \%)$ & $5(8 \%)$ & $24(41 \%)$ & & \\
occupations & & & & & & & \\
\hline Abbreviations: $N$, total number of persons; $n$, number of persons with pressure ulcer.
\end{tabular}

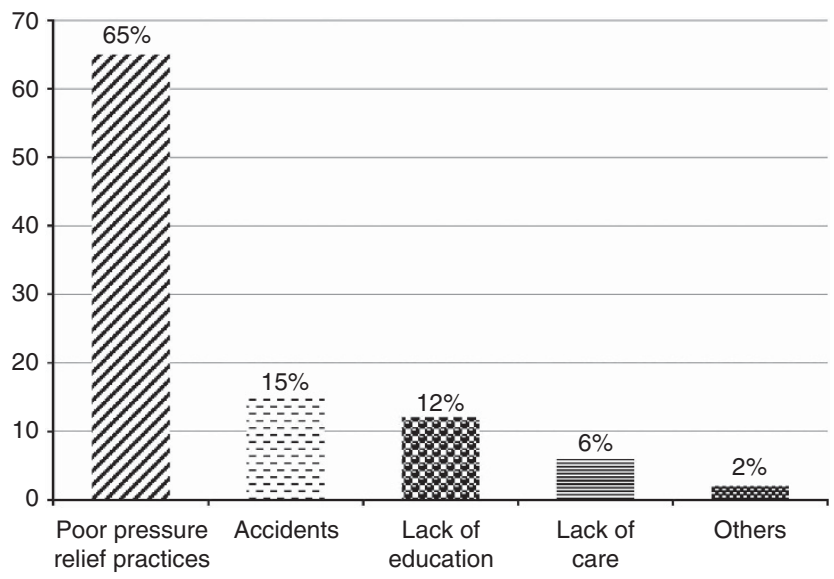

Figure 3 Causes of pressure ulcers.

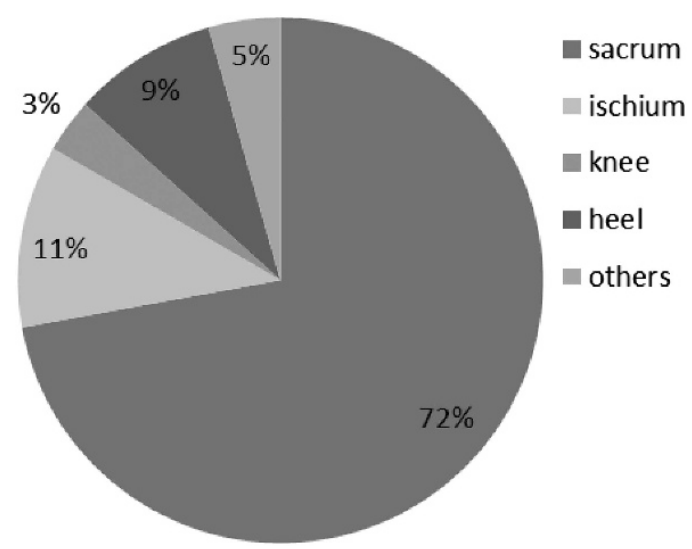

Figure 4 Distribution of location of pressure ulcers.

Employment details showed variations before and after the injury. The percentage of people in office work increased from $2 \%$ pre-injury to $8 \%$ post injury. This finding suggests that office workers have a better chance of return to work compared with other employment categories. A significant drop in the number of manual workers from 54 to $14 \%$ was also noted. This may be owing to the physical limitation caused by the injury as reported by 62 persons. The physical limitation has a greater impact on manual jobs compared with other categories.

This study did not identify any relationship between work status and PU development as the percentage of people developing ulcers 
were nearly equal among employed and unemployed people. However, a correlation between the type of work and severity of PUs was found. This showed that manual workers $(73 \%)$ had mild ulcers when compared with other employment categories. This could be because physical activity is more in manual work and hence they do not stay in the same position for a long time. We also found that persons doing home-based occupations like tailoring, cycle repair, toy making and running petty shops had severe ulcers $(41 \%)$ as they have to maintain prolonged sitting.

No statistically significant relation was identified between independence in self-care and PU development, which is contradictory to the results of a previous study that showed that those who were independent in self-care had fewer ulcers than those who were dependent. ${ }^{13,14}$ During rehabilitation, patients are taught to do regular skin inspection and $10-15 \mathrm{~s}$ of pressure relief once in every 15 min. Our study identified that most people did not follow the pressure relief practises. Most of the components of self-care like bathing, dressing and toileting require patients to be seated, and hence if adequate pressure relief practices are not followed while doing the same, this might also lead to PU development. Hence, we see that more than the status of being independent in self-care, it is the compliance to pressure relief practices that is trivial.

Contrary to the results in another study, ${ }^{15}$ our study observed that people pursued more active leisure (65\%) activities after the injury. Most of the persons who pursued active leisure activities did so by visiting friends and relatives. For this reason, they would have to travel on their wheel chair or tricycle for relatively long duration. Many of them failed to practise pressure relief strategies at this time, which had led to PU development even among participants who pursue active leisure. There are very few published studies that examine the relationship between leisure activities and PU occurrence in spinal injury. ${ }^{14}$ Therefore, it is quite hard to compare the results of this study with other studies.

The anatomical level of lesion did not show any significant relation with PU development unlike other studies, ${ }^{16}$ which noted that level of injury was related to PU development. Completeness of injury was positively correlated with $\mathrm{PU}$ development $(P=0.001)$. The participants who had complete SCI developed more PUs irrespective of their level of lesion. ${ }^{3}$ A complete injury hampers sensory perception below the level of lesion hence leading on to the development of ulcers.

Among the causes for PU development, poor pressure relief practices like prolonged sitting or lying in the same position was the most common cause. This highlights the importance of this one single factor, pressure relief practices, in the prevention of ulcers despite information given on preventive measures during rehabilitation.

This study had some limitations. As it was a retrospective crosssectional study, the participants were asked to subjectively report the development of ulcers and its severity, which restricted the use of objective PU grading. Hence, the validity of data obtained through such self-report can be challenged.

The cross-sectional design of the study enabled only to point out if there was an association between the variables and could not show a direct causative link.

Our study population had variations in distribution in terms of gender, educational status, and so on, which would have influenced the outcomes.
Future studies can be carried out using a longitudinal research design to establish cause and effect relationship between occupational activities and PU development. Studies focusing on leisure participation among Indian population and how it is related to quality of life of people can also be done as there is lack of literature on this. Further research can be carried out to identify efficacy of pressure relief practices on PU development.

\section{CONCLUSION}

This study clearly indicates that despite knowledge patients tend to have poor pressure relief practices. Poor pressure relief practices lead to PU development in persons with SCI, irrespective of their level of independence, employment status or leisure pursuits. Therefore, the role of occupational therapists in educating patients and encouraging a balanced lifestyle is inevitable. However, the role of a therapist does not end with the management at the hospital, but extends to ensure that these practices are followed at home, thereby giving the patients a better quality of life.

\section{DATA ARCHIVING}

There were no data to deposit.

\section{CONFLICT OF INTEREST}

The authors declare no conflict of interest.

\section{ACKNOWLEDGEMENTS}

We thank the Occupational Therapy Unit and the Rehabilitation Center for allowing us to accomplish this project. We thank all our colleagues for their constant support and encouragement.

1 Jang Y, Wang YH, Wang JD. Return to work after spinal cord injury in Taiwan: the contribution of functional independence. Arch Phys Med Rehabil 2005; 86: 681-686.

2 Nalina G, Solomon JM, Raja K. Demographic characteristics of individuals with paraplegia in india- a survey. Indian J Physiother Occup Ther 2008; 2: 24-27.

3 Correa GI, Fuentes M, Gonzalez X, Cumsille F, Pineros FL, Finkelstein J. Predictive factors for pressure ulcers in the ambulatory stage of spinal cord injury patients. Spinal Cord 2006; 44: 734-739.

4 Gelis A, Dupeyron A, Legros P, Benaim C, Pleissier J, Fattal C. Pressure ulcer risk factors in persons with spinal cord injury part 2: the chronic stage. Spinal Cord 2009; 47: 651-661.

5 Hoff JM, Bierke LW, Gravem PE, Hagen EM, Rekand T. Pressure ulcers after spinal cord injury. Norwegian 2012; 132: 838-839.

6 National Spinal Cord Injury Statistical Center. Spinal Cord Injury: Facts and Figures at a Glance. NSCISC: Birmingham, AL, 2000.

7 Kielhofner G. Conceptual Foundations of Occupational Therapy, 2nd edn. FA Davis: Philadelphia, 1997.

8 Engehard HT. Defining occupational therapy: the meaning of therapy and the virtues of occupation. Am J Occup Ther 1997; 32: 666-672.

9 Miller BRJ, Sieg KW, Ludwig FM, Shortridge SD, Van Deusen J. Six Perspectives on Theory for Practice of Occupational Therapy. Aspen: Rockville, MD, 1988.

10 Reilly M. Occupational therapy can be one of the great ideas of 20th century medicine. Am J Occup Ther 1962; 20: 60-67.

11 Rebeiro KL, Polgar JM. Enabling occupational performance: optimal experiences in therapy. Can J Occup Ther 1999; 66: 14-22.

12 Tomassen PCD, Post MWM, Van Asbeck FWA. Return to work after spinal cord injury. Spinal Cord 2000; 38: 51-55.

13 Lidal IB, Huynh TK, Biering-Sorensen F. Return to work following spinal cord injury: a review. Disabil Rehabil 2007; 29: 1341-1375.

14 Cutajar R, Roberts A. The relationship between engagement in occupations and pressure sore development in Saudi men with paraplegia. Br J Occup Ther 2005; 68 : 307-314.

15 Tasiemski T, Bergstro Èm E, Savic G, Gardner BP. Sports, recreation and employment following spinal cord injury: a pilot study. Spinal Cord 2000; 38: 173-184.

16 Anderson TP, Andberg MM. Psychosocial factors associated with pressure ulcers. Arch Phys Med Rehabil 1979; 60: 341-346. 


\section{QUESTIONNAIRE}

\section{Data Form}

Name:
Age: Years
(1) $16-40$
(2) $41-65$

Sex: (1) Male

(2) Female

Educational status
(1) Illiterate
(2) Primary
(3) Higher Secondary
(4) College

Marital status
(1) Single
(2) Married
(3) Widowed
(4) Separated/divorced

Date of injury

Level of injury
(1) High-level thoracic
(2) Low-level thoracic
(3) Lumbar
(4) Sacral

Complete/incomplete

Mark whichever is applicable to you. If none are applicable, leave the space blank.
(A) Have you been working after your injury?
(1)Yes
(2) No
(B) If you are employed, is it
(1) Paid
(2) Unpaid (e.g., volunteer)

(C) Do you work? (1) Part time (up to 4 hours)

(2) Full time ( 8 hours or more)

(D) What is the type of work you do?
(1) Office work
(2) Manual work (carpenter, farmer, daily laborer)
(3) Others (shopkeeper, cycle repair, tailoring and security)

(E) How do you rate your satisfaction with your work?
(1) Satisfied
(2) Partially satisfied
(3) Unsatisfied

(F) What was your previous vocation? (Before injury)
(1) Office work
(2) Manual work
(3) Others
(4) Unemployed

(G) Are you still continuing the same vocation? (1) Yes (2) No

(H) If no, reason for discontinuing:

(1) Owing to physical limitation caused by the injury

(2) Difficulty in transportation

(3) Both

(4) Others

(I) What is your monthly income?
(A) Do you engage in any leisure activities?
(1) Yes
(2) No
(B) If yes, is it:
(1) Active leisure (which involves movement, e.g., playing games, visiting friends etc.)
(2) Passive leisure (which can be done in sitting, e.g., reading books, watching TV)
(3) Both
(C) How many hours in a day do you spend on leisure?

(A) Do you require any assistance for your self-care activities (bathing and transferring)
(1) Yes
(2) No

(B) If yes, how much of assistance do you require?
(1) Minimal
(2) Moderate
(3) Maximal
(4) Setup

(A) Have you ever developed any pressure ulcers after your injury?
(1) Yes
(2) No

(B) How many pressure ulcers have you developed till date after the injury?

(C) Where is the location of your pressure ulcer? (If you have more than one pressure ulcer mention each one separately)

(1) Near buttocks (sacrum)

(2) Near hips (ischium)

(3) Near the knee

(4) Near the heel

(5) Others

(D) How do you rate the severity of your pressure ulcer?
(1) Mild
(2) Moderate
(3) Severe

(E) Did you require any hospitalizations for your pressure ulcers? (1) Yes (2) No

(F) How many times were you hospitalized for your pressure ulcer?

(G) Was any treatment procedure done? (1) Yes (2) No
(H) If yes, is it
(1) Dressing
(2) Surgery
(3) Others 
Choose the most appropriate cause for your pressure ulcer from the list given below. If none of them apply, specify the reason for your pressure ulcer in 'others'.
(1) Lack of sensation
(2) Lack of proper instructions from hospital
(3) Could not follow guidelines at home
(4) Damage to skin occurred during transfer
(5) Following an accident (e.g., skin burn)
(6) Prolonged sitting or lying in one position
(7) Following any medical procedure (e.g., injection)
(8) Owing to poor skin hygiene and inadequate skin inspection
(9) During self-care activities like bathing, etc.
(10) Others: 